\title{
Korjuutappiot ja paalintiheys ruokohelven kevätkorjuussa
}

Timo Lötjönen

MTT (Maa- ja elintarviketalouden tutkimuskeskus), Tutkimusasemantie 15, 92400 Ruukki

timo.lotjonen@mtt.fi

\section{Tiivistelmä}

Kuivan ja lakoutuneen ruokohelven kevätkorjuussa tapahtuu väistämättä korjuutappioita. Aiemmissa tutkimuksissa helven niitossa ja korjuussa on jopa 40 - 50 \% sadosta jäänyt peltoon ylipitkänä sänkenä tai murentuneena silppuna.

Myös ruokohelpipaalien tiheys ja käsittelyn kestävyys ovat olleet monesti alhaisia. Löysistä paaleista on saatu tehtyä kuljetusrekkoihin kuormia, joiden massat ovat olleet vain puolet siitä, mitä ovat tiukoista paaleista tehtyjen kuormien massat. Löysien paalien muoto muuttuu lastauksen aikana, jolloin ne vievät enemmän tilaa, kuin on suunniteltu. Näistä syistä löysien paalien kuljettaminen on liian kallista verrattuna niiden energiasisältöön ja paalien pitäisikin olla mahdollisimman tiukkoja.

Keväällä 2007 toteutettiin Haapavedellä kaksi kenttäkoetta, joiden tavoitteena oli löytää korjuumenetelmiä, joilla päästään pieniin korjuutappioihin ja suuriin paalien tiukkuuksiin. Niittokokeessa verrattiin erilaisia niitto- ja karhotusmenetelmiä ja paalauskokeessa muutamaa pyöröja kanttipaalainta.

Niittokokeessa saatiin talteen $70-80 \quad \% \quad$ keväällä pellolla olleesta biomassasta. Lautasniittokoneelle ja ajettavalle niittokoneelle, swatherille, nämä ovat tyypillisiä arvoja. Yllättävää olivat niittomurskaimen pienet korjuutappiot (saanto $80 \%$ ), kun hinattavalla niittomurskaimella saanto on yleensä ollut 50 - 60 \%. Kokeessa olleessa koneessa oli kaukosäädettävä leikkuukorkeus ja hellävarainen murskainosa, jotka voivat selittää tulosta. Viereisessä paalauskokeessa korjuusaanto oli vain $55 \%$, vaikka käytettiin hyväksi otaksuttua lautasniittokoneen ja karhottimen yhdistelmää. Niittourakoitsija oli säätänyt koneensa hieman liian pitkään sänkeen mahdollisten kivien varalta ja tämä näkyi heti korjuusaannon heikentymisenä. Tämän ja edellisvuosien kokeiden perustella näyttää siltä, että 80 \% korjuusaantoa on hyvin vaikea ylittää, koska ruokohelpi on melkein aina keväällä pahasti laossa ja haurasta.

Paalauskokeessa suurin paalintiheys saatiin aikaan uudella suurkanttipaalaimella $\left(201 \mathrm{~kg} / \mathrm{m}^{3}\right.$, kosteus $15 \%$ ). Paalit olivat hyvänmuotoisia ja ne kestivät hyvin siirtelyä ja kuljetusta. Vanhemman tyyppisellä kanttipaalaimella ei saatu yhtä tiiviitä paaleja, paalien tiheys oli keskimäärin $161 \mathrm{~kg} / \mathrm{m}^{3} 15$ \%:n kosteudessa. Materiaalin syötössä paalikammioon on tapahtunut teknistä kehitystä 10 vuoden aikana, josta ero johtunee. Pyöröpaalaimilla päästiin $166-172 \mathrm{~kg} / \mathrm{m}^{3}$ paalintiheyksiin. Kiinteä- ja muuttuvakammioisen paalaimen paalintiheyksissä ei ollut eroja, mikä on hieman yllättävää, sillä aiemman tutkimustiedon valossa on ajateltu, että muuttuvakammioisella saadaan kiinteäkammioista paalainta tiukemmat paalit. Ilmeisesti pyöröpaalainmerkkien välillä on teknisiä eroja, jotka selittävät saatua tulosta.

Asiasanat: ruokohelpi, kevätkorjuu, korjuutappiot, niitto, paalaus, paalintiheys 


\section{Johdanto}

Ruokohelven (Phalaris arundinacea L.) viljelyala on viime vuosina lisääntynyt Suomessa nopeasti. Helven viljelyala oli vuonna 2007 hieman yli 20000 ha, mikä vastaa lähes $1 \%$ maamme kokonaisviljelyalasta (Tike 2007). Ruokohelpi on nyt merkittävin pelloillamme viljeltävä bioenergiakasvi. Toisaalta tällä hetkellä korkea viljanhinta saattaa vähentää kiinnostusta viljelyalan kasvattamiseen.

Ruokohelpi on monivuotinen heinäkasvi, joka tuottaa yhdellä kylvöllä satoa yli 10 vuotta, kun korjuu tehdään keväällä. Sen polttoaineominaisuudet paranevat, kun kasvuston annetaan olla pellolla talven yli seuraavaan kevääseen, jolloin ravinteet kerääntyvät juuristoon ja vesi huuhtoo pois polttokattiloille haitallisia aineita (Pahkala ym. 2005). Tärkein kevätkorjuun etu on kuitenkin se, että keväällä kasvuston kosteus on vain 10 - $15 \%$, kun se syksyllä saattaa olla esimerkiksi $50 \%$.

Nopeasti uusiutuvana biomassakasvina ruokohelpi on $\mathrm{CO}_{2}$-neutraali ja siten kiinnostava polttoaine päästökaupan piirissä oleville voimalaitoksille. On arvioitu, että ruokohelpeä voisi käyttää 70 - 80 voimalaitosta Suomessa (Flyktman \& Paappanen 2005). Nykyään yli 20 voimalaitosta on jo kokeillut helven käyttöä polttoaineena.

Ruokohelven tuotantoketju kaipaa kuitenkin kehittämistä, jotta tuotantokustannuksia saataisiin leikattua. Helven kevätkorjuussa tapahtuu väistämättä korjuutappioita, koska kasvusto on pahasti laossa ja haurasta. Mittausten mukaan jopa 40 - 50 \% kasvustosta on jäänyt pellolle liian pitkänä sänkenä tai varisemistappioina (Lötjönen \& Isolahti 2007). Ennestään tiedetään, että suuria tappioita voi syntyä, mikäli niittolaitteen niittokorkeutta ei ole säädetty tarpeeksi matalaksi (Pahkala ym. 2005). Lisäksi tiedetään, että niittomurskaimen käyttöä niitossa tulisi välttää tai murskainosan kierrosnopeus pitäisi ainakin säätää mahdollisimman alhaiseksi turhan varisemisen estämiseksi.

Ruokohelpipaalien tiheys ja käsittelyn kestävyys ovat usein olleet liian alhaisia. Löysillä paaleilla lastatun rekka-auton kuorman massa (10 tonnia) on saattanut olla vain puolet siitä, mitä on tiukoista paaleista tehdyn kuorman massa (20 tonnia). Löysät paalit muuttavat muotoaan lastattaessa tai voivat jopa hajota ja vievät siten ennalta arvioitua enemmän tilaa. Näistä syistä löysien paalien kuljettaminen on liian kallista suhteessa niiden energiasisältöön. Ennestään tiedetään, että muuttuvakammioisella pyöröpaalaimella saadaan kiinteäkammioista paalainta hieman tiiviimpiä paaleja. Paalien tiheyden ja muodon kannalta paras paalaintyyppi olisi kuitenkin suurkanttipaalain (Pahkala ym. 2005).

Tämän tutkimuksen tavoitteena oli 1) löytää niittomenetelmiä, joilla korjuutappiot jäävät mahdollisimman pieniksi ja 2) paalausmenetelmiä, joilla saadaan mahdollisimman tiiviitä paaleja. Tutkimus on osa laajempaa vuonna 2006 alkanutta hanketta, jossa MTT:n vastuulla on ruokohelven korjuutekniikan ja VTT:n vastuulla logistiikan ja polttolaitospään kehittäminen. Tavoitteena on koko tuotantoketjun kustannusten leikkaaminen. Hankkeen päärahoittaja on Tekes.

\section{Aineisto ja menetelmät}

Tavoitteiden saavuttamiseksi keväällä 2007 perustettiin kaksi kenttäkoetta Haapavedelle, Vapon ruokohelpiviljelmälle. Niitto- ja karhotuskokeessa tutkittiin lautaskoneen, niittomurskaimen ja ajettavan swather-niittokoneen vaikutuksia korjuusaantoon. Lisäksi verrattiin ns. "normaalia" säilörehukarhotinta ja uudentyyppistä Elho-karhotinta.

Paalauskokeessa verrattiin kiinteä- ja muuttuvakammioisen pyöröpaalaimen ja toisaalta uudenmallisen ja vanhemmanmallisen kanttipaalaimen vaikutusta paalien tiheyteen. Muuttuvakammioista paalainta käytettiin silppurilla (14 terää) sekä ilman. Samalla mitattiin korjuusaanto eli mahdolliset erot varisemistappioissa. Koekäsittelyt on esitetty taulukossa 1. Käsittelyjen valinnassa voitiin hyödyntää aikaisempien tutkimusten kokemuksia (Pahkala ym. 2005, Larsson ym. 2006, Lötjönen \& Isolahti 2007).

Kokeet järjestettiin kolmella toistolla ja koekaistojen koko oli niittokokeessa noin 0,25 ha ja paalauskokeessa 0,50 ha. Kokeiden aluksi koekaistoilta määritettiin keskimääräinen biologinen sato Haldrup-koeruutupuimurilla. Mittaus tehtiin viisi kertaa jokaiselta koekaistalta kaistojen suuntaisesti ajaen ja yhden mittauksen pinta-ala oli noin $15 \mathrm{~m}^{2}$.

Toukokuun sateet viivyttivät varsinaisen korjuun touko-kesäkuun vaihteeseen. Koekaistat niitettiin, karhotettiin ja paalattiin aina yksi kerrallaan, eli jokaiseen kaistaan tuli ajoa myötä- sekä 
vastalakoon. Koneiden säätöjä ei lähdetty erikseen optimoimaan, vaan kuljettajille annettiin ohjeet niittää niin tarkasti kuin mahdollista ja tehdä niin tiukkoja paaleja kuin pystyvät. Koetta ennen annettiin mahdollisuus harjoitella ja tehdä säätöjä.

Taulukko 1. Koekäsittelyt ja kokeissa käytetyt koneet Haapavedellä keväällä 2007.

\begin{tabular}{|c|c|c|c|}
\hline $\begin{array}{l}\text { Niitto- ja } \\
\text { karhotuskoe }\end{array}$ & Niitto & Karhotus & Paalaus \\
\hline Käsittely 1. & Elho NK 280 lautaskone & $\begin{array}{l}\text { Pöttinger 2- } \\
\text { roottorinen karhotin }\end{array}$ & $\begin{array}{l}\text { New Holland BB950A } \\
\text { suurkanttipaalain }\end{array}$ \\
\hline Käsittely 2. & Elho NK 280 lautaskone & $\begin{array}{l}\text { Elho VT Twin } \\
\text { karhotin }\end{array}$ & $\begin{array}{l}\text { New Holland BB950A } \\
\text { suurkanttipaalain }\end{array}$ \\
\hline Käsittely 3. & $\begin{array}{l}\text { Elho HNM } 320 \text { C } \\
\text { hinattava niittomurskain }\end{array}$ & $\begin{array}{l}\text { Pöttinger 2- } \\
\text { roottorinen karhotin }\end{array}$ & $\begin{array}{l}\text { New Holland BB950A } \\
\text { suurkanttipaalain }\end{array}$ \\
\hline Käsittely 4. & $\begin{array}{l}\text { Hesston itsekulkeva } \\
\text { swather }\end{array}$ & $\begin{array}{l}\text { Pöttinger 2- } \\
\text { roottorinen karhotin }\end{array}$ & $\begin{array}{l}\text { New Holland BB950A } \\
\text { suurkanttipaalain }\end{array}$ \\
\hline
\end{tabular}

\begin{tabular}{|c|c|c|c|}
\hline Paalauskoe & Niitto & Karhotus & Paalaus \\
\hline Käsittely A. & $\begin{array}{l}\text { Pöttinger } 305 \mathrm{H} \\
\text { lautaskone }\end{array}$ & $\begin{array}{l}\text { Pöttinger 2- } \\
\text { roottorinen karhotin }\end{array}$ & $\begin{array}{l}\text { Welger RP 220, } \\
\text { kiinteäkammioinen } \\
\text { pyöröpaalain, ei silppuria }\end{array}$ \\
\hline Käsittely B. & $\begin{array}{l}\text { Pöttinger } 305 \mathrm{H} \\
\text { lautaskone }\end{array}$ & $\begin{array}{l}\text { Pöttinger 2- } \\
\text { roottorinen karhotin }\end{array}$ & $\begin{array}{l}\text { Vicon RV 1601, } \\
\text { muuttuvakammioinen } \\
\text { pyöröpaalain, ei silppuria }\end{array}$ \\
\hline Käsittely C. & $\begin{array}{l}\text { Pöttinger } 305 \mathrm{H} \\
\text { lautaskone }\end{array}$ & $\begin{array}{l}\text { Pöttinger 2- } \\
\text { roottorinen karhotin }\end{array}$ & $\begin{array}{l}\text { Vicon RV 1601, } \\
\text { muuttuvakammioinen } \\
\text { pyöröpaalain, silppuri }\end{array}$ \\
\hline Käsittely D. & $\begin{array}{l}\text { Pöttinger } 305 \mathrm{H} \\
\text { lautaskone }\end{array}$ & $\begin{array}{l}\text { Pöttinger 2- } \\
\text { roottorinen karhotin }\end{array}$ & $\begin{array}{l}\text { New Holland BB950A, } \\
\text { kanttipaalain, ei silppuria }\end{array}$ \\
\hline Käsittely E. & $\begin{array}{l}\text { Pöttinger } 305 \mathrm{H} \\
\text { lautaskone }\end{array}$ & $\begin{array}{l}\text { Pöttinger 2- } \\
\text { roottorinen karhotin }\end{array}$ & $\begin{array}{l}\text { Claas Quadrant 1200, vm } \\
\text { 1997, kanttipaalain, ei } \\
\text { silppuria }\end{array}$ \\
\hline
\end{tabular}

Saadut paalit punnittiin yksitellen paalivaa'alla. Talteen saatu helpisato (\%) laskettiin seuraavasti: Paalien kuiva-ainemassa/ Biologisen sadon kuiva-ainemassa x 100 \%. Paalauskokeessa mitattiin myös paalien todelliset ulkomitat, jotta paalien tiheys voitiin laskea.

\section{Tulokset ja tulosten tarkastelu}

\section{Niitto- ja karhotuskoe}

Ruokohelpi oli kasvanut molemmilla koealueilla hyvin, koeruutupuimurilla mitattu biologinen kuivaainesato oli 7000 - 9000 kg/ha. Niitto- ja karhotuskokeessa lautasniittokoneen jäljiltä saatiin talteen 70 - $75 \%$ ja niittomurskaimen ja swatherin jälkeen noin 80 \% biologisesta sadosta (kuva 1). Lautaskoneelle ja swatherille nämä ovat tyypillisiä arvoja, mutta niittomurskain toimi tässä kokeessa paremmin kuin aiemmin. Yleensä talteen saatu sato niittomurskaimen jäljiltä on ollut vain $50-60 \%$ (Lötjönen \& Isolahti 2007). 
Kokeessa käytetyssä niittomurskaimessa (käsittely 3) oli kaukosäädettävä leikkuukorkeuden säätö ja putkisormin toteutettu murskainosa, jotka saattavat selittää tulosta. Kun leikkuukorkeus on helposti säädettävissä, säätö tulee myös tehtyä. Putkisormimurskain voi olla hellävaraisempi kuin muut murskaintyypit. Murskainosan kierrosnopeus oli myös säädetty hitaimmaksi mahdolliseksi. Itsekulkevalla swatherilla (käsittely 4) korjuusaanto oli hyvä, koska siinä on samanlainen leikkuupöytä kuin leikkuupuimurissa. Siten lakoista helpikasvustoa voidaan kohottaa ennen kuin teräpalkki katkaisee sen. Swatherilla ajetaan kuten puimurilla, joten sen ajonopeus on hitaampi ja kapasiteetti heikompi kuin samanlevyisillä lautaskoneilla.

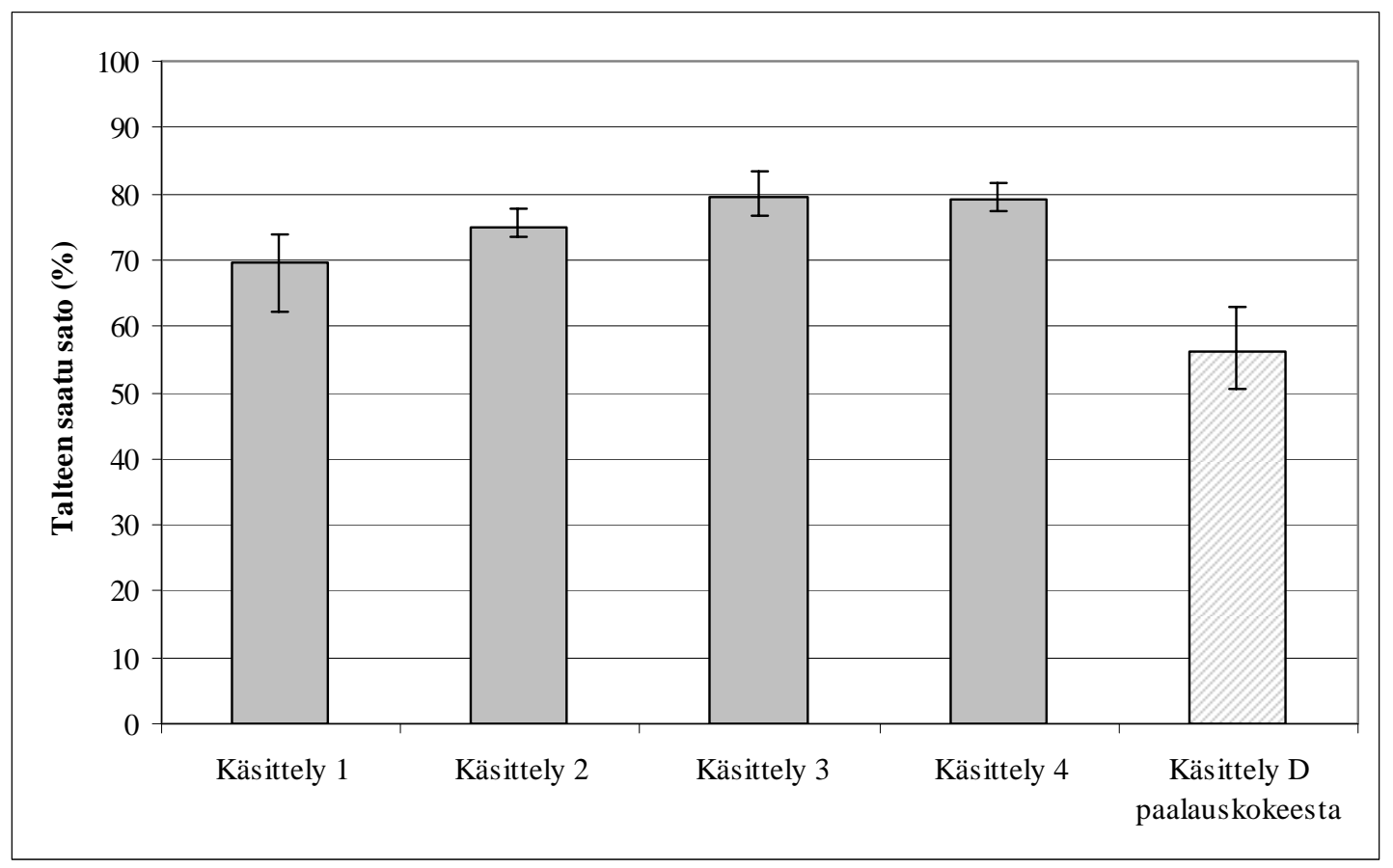

Kuva 1. Talteen saatu ruokohelpisato Niitto- ja karhotuskokeessa. Käsittelyt on esitetty taulukossa 1. Viimeinen käsittely on otettu paalauskokeesta, joka järjestettiin viereisellä lohkolla. Janat ilmaisevat mitatut minimi- ja maksimiarvot.

Karhottimien väliset erot (käsittelyt 1 ja 2) korjuusaannolla mitattuna olivat pieniä (kuva 1). Käytännössä Elho VT-karhottimen runkorakenne oli murskaamattomalle ruokohelvelle turhan matala, jolloin karhotin keräsi helvestä kasoja karheeseen ja tukkeutuminen oli lähellä. Runkorakenteen avartamisen jälkeen kone sopinee ruokohelvellekin hyvin.

Paalauskokeessa lautasniittokoneen leikkuukorkeus oli säädetty hieman turhan korkealle, koska koneen omistaja pelkäsi pellolla mahdollisesti olevia kiviä. Tämä näkyi 15 prosenttiyksikön korjuutappiona, jos vertaamme käsittelyjä 1 ja D kuvassa 1 . Vaikka nämä käsittelyt ovatkin eri kokeista, ovat ne melko vertailukelpoisia. Kokeet sijaitsivat vierekkäisillä lohkoilla ja käsittelyt 1 ja D korjattiin samalla tavalla, ainoastaan niittokoneet säätöineen olivat erilaiset.

\section{Paalauskoe}

Paalauskokeessa suurin keskimääräinen paalintiheys saatiin New Holland kanttipaalaimella (201 $\mathrm{kg} / \mathrm{m}^{3}$, kosteus $15 \%$ ) (kuva 2). Paalit olivat hyvänmuotoisia ja ne kestivät hyvin nostelua ja siirtelyä. Vanhempi Claas kanttipaalain ei tehnyt yhtä tiukkoja paaleja, paalintiheys oli keskimäärin $161 \mathrm{~kg} / \mathrm{m}^{3}$ 15 \%:n kosteudessa. Materiaalin syötössä paalikammioon on tapahtunut teknistä kehitystä 10 vuoden aikana, on tullut ns. esikammiotekniikka, joka voi selittää eroa. Lisäksi vanhemmassa paalaimessa oli omistajan mukaan merkittäviä vikoja, jotka on saatu nyttemmin korjattua.

Pyöröpaalaimilla päästiin $166-172 \mathrm{~kg} / \mathrm{m}^{3}$ paalintiheyksiin. Kiinteä- ja muuttuvakammioisen paalaimen paalintiheyksissä ei ollut juurikaan eroja, mikä on hieman yllättävää, sillä aiemman tutkimustiedon valossa on ajateltu, että muuttuvakammioisella saadaan kiinteäkammioista paalainta 
tiukemmat paalit (mm. Pahkala ym. 2005). Ilmeisesti kiinteäkammioisten paalainten välillä on tiettyjä teknisiä eroja, jotka selittävät saatua tulosta. Kiinteäkammioisessa paalaimessa oleellista on peräportin lukitus, joka estää kammion avautumisen ennenaikaisesti. Verrattaessa pyörö- ja kanttipaalainten paalintiheyksiä toisiinsa, on huomattava, että esitetyt luvut koskevat vain paalien sisäistä tiheyttä, ts. siinä ei ole huomioitu kanttipaalien parempaa tilankäyttöä esim. rekka-autoon kuormattaessa.

On myös esitetty, että kiinteäkammioinen paalain varistaa merkittävästi helpeä rullien välistä. Näin voi ollakin, jos ruokohelpi on hyvin kuivaa ( $<10 \%)$, mutta tässä kokeessa helven kosteus oli kahtapuolta $15 \%$, eikä varisemiseroja kiinteä- tai muuttuvakammioisen tai toisaalta kanttipaalainten välillä mittausten mukaan ollut.

Muuttuvakammioisessa paalaimessa silppurin käyttö (14 terää) ei lisännyt paalintiheyttä (käsittely B vs. C). Varisemistappiot sen sijaan kasvoivat hieman, noin 4 \%. Silppuamisesta voisi olla hyötyä voimalaitoksella paalinpurkuvaiheessa. VTT:n mittausten mukaan silppu ei kuitenkaan ollut tarpeeksi lyhyttä, jotta se kulkisi ongelmitta voimalaitosten kuljettimissa.

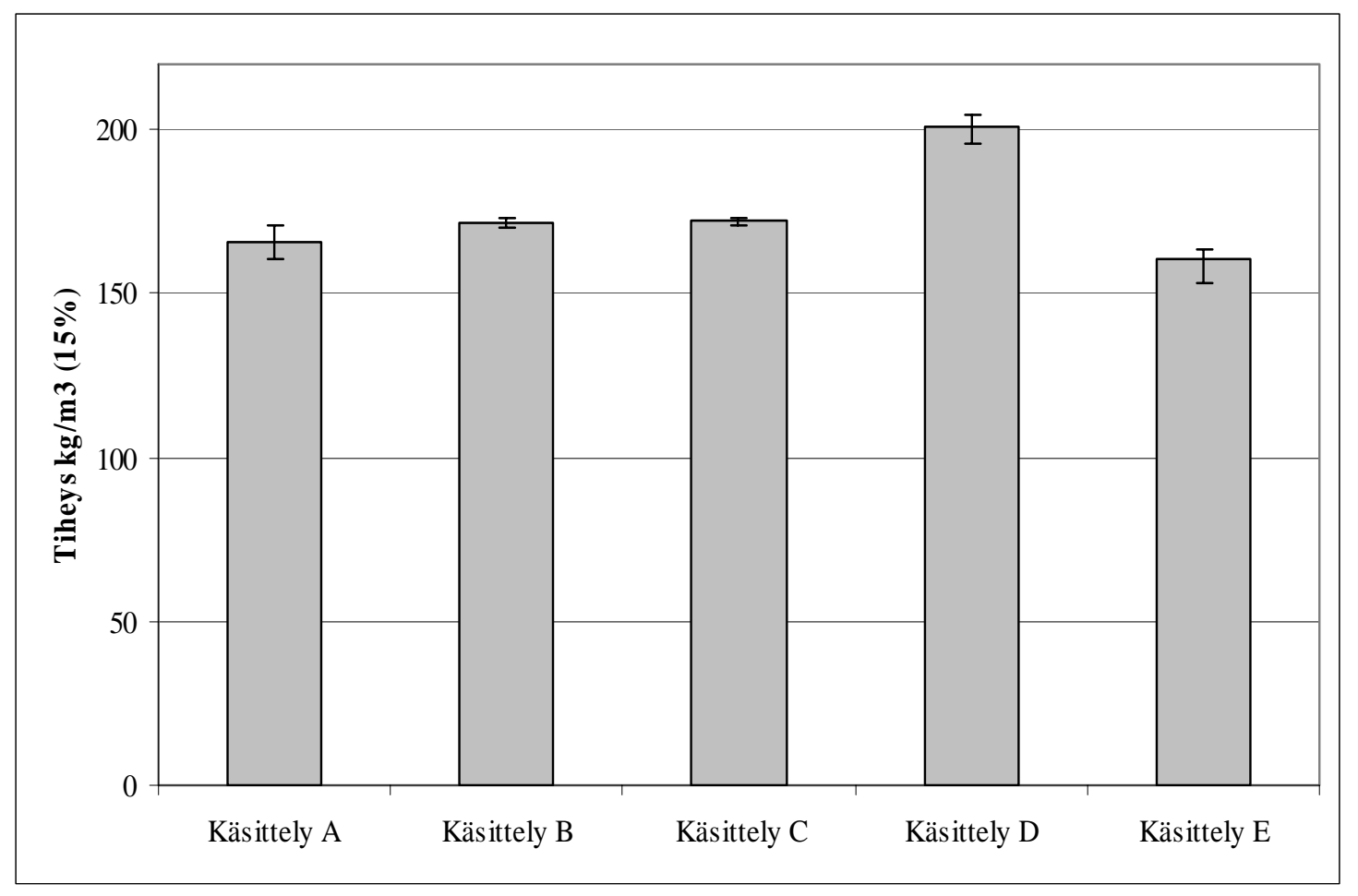

Kuva 2. Paalauskokeen keskimääräiset paalintiheydet $\left(\mathrm{kg} / \mathrm{m}^{3}\right) 15 \%$ kosteudessa. Käsittelyt on esitetty taulukossa 1. Janalla on merkitty pienin ja suurin mitattu arvo.

Kun paaleja lastataan kuljetusautoon, on oleellista, että kuormatilaan saadaan mahtumaan kaksi paalia rinnakkain. Jos kuormatila on vähänkin liian kapea tai paalit epäsäännöllisen muotoisia, tämä ei onnistu ja kuormaan jää paljon tyhjää. Oletetaan, että näin ei käy ja käytössä on lavamitoiltaan lähes suurin mahdollinen kuljetusauto. Tällöin kokeessa mitatuilla paalien tiheyksillä laskennalliset rekan helpikuorman kuiva-ainemassat olisivat seuraavat: A) kiinteäkammioinen pyöröpaalain ( $\mathrm{d}=1,3 \mathrm{~m})$ 15,4 tonnia, B) muuttuvakammioinen pyöröpaalain $(\mathrm{d}=1,6 \mathrm{~m}) 16,6$ tonnia ja $\mathrm{D})$ kanttipaalain $(1,2 \mathrm{x}$ $0,7 \times 2,4 \mathrm{~m}) 23,4$ tonnia. Kanttipaalaimella on siis mahdollista saavuttaa noin $50 \%$ suurempi kuormapaino kuin pyöröpaalaimella. Käytännössä ero voi olla suurempikin, sillä Vapon mukaan kevyimmät pyöröpaalikuormat ovat painaneet alle 10 tonnia.

\section{Johtopäätökset}

Tämän ja aikaisempien tutkimusten mukaan lautasniittokoneella, niittomurskaimella ja swatherilla on kaikilla mahdollista päästä 80 \% korjuusaantoon ruokohelven kevätkorjuussa (Lötjönen \& Isolahti 2007). Tämä on monesti jo riittävän hyvä tulos. Lautasiin perustuvassa niitossa oleellista on teräpalkin kulman säätö tarpeeksi jyrkäksi, jotta myötälakoinenkin kasvusto katkeaa tarpeeksi lyhyeen sänkeen. 
Myötälaon niitto on kaikkein hankalinta. Nostolaitekoneissa säätö on yleensä helpompi tehdä kuin hinattavissa koneissa. Toisaalta teräpalkin kulmaa kasvatettaessa kasvaa myös riski kalliille terävaurioille, mikäli pellolla on kiviä, kantoja tai painaumia. Siksi varsinkin urakoitsijat tyytyvät mieluummin vähän pitempään sänkeen kuin ottavat rikkoutumisriskin.

Niittomurskainta käytettäessä toinen oleellinen säätö on murskainosan säätäminen mahdollisimman hellävaraiseksi sen kierrosnopeutta alentamalla ja vastakampaa löysäämällä. Hyvin kuivassa kasvustossa murskainosa voi silti aiheuttaa varisemistappioita, jolloin pelkän lautasniittokoneen käyttö olisi parempi vaihtoehto. Toisaalta murskainta käytettäessä voidaan välttyä karhottamisvaiheelta, sillä murskain tekee karhot, joissa on riittävästi massaa pienempitehoisille korjuukoneille, esimerkiksi pyöröpaalaimille.

Paalauskokeessa kävi ilmi, että hyvällä kiinteäkammioisella pyöröpaalaimella on mahdollista päästä yhtä suuriin paalintiheyksiin kuin muuttuvakammioisellakin paalaimella. Myöskään varisemistappioissa ei ollut eroja. Nämä ovat uudenlaisia tuloksia verrattuna aiempaan tietoon (Pahkala ym. 2005). Tässä kokeessa helpi ei ollut äärimmäisen kuivaa, mikä voi selittää tuloksia. Muuttuvakammioisen paalaimen etuna on, että sillä voidaan tehdä kiinteäkammioista suurempia paaleja, joilla voi olla parempi tilankäyttö kuljetusajoneuvoissa, kuten tämän tutkimuksen ajoneuvotarkastelussa kävi. Silpputerien käyttö ei näyttäisi pyöröpaalaimessa kannattavan, koska paalintiheys ei nouse ja toisaalta variseminen voi lisääntyä hieman.

Kanttipaalaimissa on tapahtunut kehitystä siten, että uudella paalaimella voidaan saada noin 25 $\%$ tiiviimmät paalit kuin esimerkiksi 10 vuotta vanhalla mallilla. Tosin otos tässä oli hyvin pieni (2 paalainta) ja vanhemmassa paalaimessa oli vikoja, jotka voivat vaikuttaa paalien tiheyteen.

Kanttipaalainta käytettäessä voidaan saavuttaa noin 50 \% suurempi kuljetusauton kuorman massa kuin pyöröpaaleja käytettäessä, koska kanttipaalien muoto ja tiheys ovat parempia. Tämä edellyttää, että paalit ovat täsmälleen oikean kokoisia ja muotoisia ja että niiden lastaus onnistuu suunnitellusti. Maassamme on kuitenkin käytettävissä paljon enemmän pyöröpaalaimia kuin kanttipaalaimia ja pyöröpaalain on kanttipaalainta huomattavasti kevyempi ja edullisempi kone, joten pyöröpaalain tulee hyväksyä ruokohelven korjuussa vielä pitkään. Tosin on niin, että kaukokuljetukseen menevää helpeä ei tulisi korjata löysiä ja huonomuotoisia paaleja tekevillä paalaimilla.

\section{Kirjallisuus:}

Flyktman, M.\& Paappanen, T. 2005. Ruokohelven käyttökapasiteettiselvitys. VTT. PRO2105/05. 28 s. + liitt. $3 \mathrm{~s}$.

Larsson, S., Örberg, H., Kalén, G. \& Thyrel, M. 2006. Rörflen som energigröda. BTK-rapport 2006:11. Sveriges Lantbruksuniversitet, Enheten för Biomassateknologi och Kemi. Umeå: SLU. 43 s.

Lötjönen, T. \& Isolahti, M. 2007. Ruokohelven korjuutappiot pienemmiksi. Koetoiminta ja käytäntö 64, 1(19.3.2007): 14.

Pahkala, K., Isolahti, M., Partala, A., Suokannas, A., Kirkkari, A-M., Peltonen, M., Sahramaa, M., Lindh, T., Paappanen, T., Kallio, E. \& Flyktman, M. 2005. Ruokohelven viljely ja korjuu energian tuotantoa varten. Maa- ja elintarviketalous nro 1. 2. korjattu painos. Jokioinen: MTT. $30 \mathrm{s.}$

Tike 2007. Peltokasvitilastot. Maa- ja metsätalousministeriön Tietopalvelukeskuksen sähköinen tietopalvelu Matilda. http://www.matilda.fi . Viitattu 16.11.2007. 